\title{
Effects of Graphene Monolayer Coating on the Optical Performance of Remote Phosphors
}

\author{
M. YAZDAN MEHR, ${ }^{1,2,3}$ S. VOLGBERT, ${ }^{2}$ W.D. VAN DRIEL, ${ }^{2}$ \\ and G.Q. ZHANG ${ }^{2}$ \\ 1.-Materials Engineering Faculty, Isfahan University of Technology, Isfahan, Iran. 2.-EEMCS \\ Faculty, Delft University of Technology, Delft, The Netherlands. 3.—e-mail: m.yazdanmehr@tudelft.nl
}

A graphene monolayer has been successfully coated on one side of a bisphenolA-polycarbonate (BPA-PC) plate, used as a substrate for remote phosphor applications in light-emitting diode (LED)-based products. Using a photoresist transferring method, graphene sheet has been coated on BPA-PC plates. The results show that this graphene monolayer significantly improves the lifetime and performance of LEDs mainly by protecting them against external degradation factors such as moisture and oxygen. Also, LED-based products composed of graphene-coated BPA-PC plates exhibit longer stability with comparatively less loss of luminous efficiency. This method has great potential to significantly improve the reliability of not only LED-based products but also many other microelectronics packaging and components, in which moisture and oxygen are the key causes of failures.

Key words: Light-emitting diode, graphene, remote phosphor, reliability

\section{INTRODUCTION}

A solid-state lighting system is composed of an LED chip with electronic driver(s) integrated in a package that provides optical functions, thermal management and/or other functions. Currently, there are different technologies used to produce white light high-power LED systems. ${ }^{4-8}$ The most common one is combining a blue chip with yellow phosphor. In such a system, the phosphor layer can be either deposited directly on the chip or incorporated into a lens disk. ${ }^{9-13}$ Moreover, white LEDs are multipart systems. Apparently, each of these components can break and induce failure, leading to a reduction of light intensity and even early failure before the expected lifetime of the instrument. Numerous investigations have been performed on various parts of LED-based products; however, not much has been done on the lens/remote phosphors of the LEDs. ${ }^{1-19}$ Recent reliability studies ${ }^{14-19}$ have shown that the optical degradation of white LED products is mainly due to the aging of the

(Received December 20, 2016; accepted May 13, 2017; published online May 26, 2017) encapsulants/lens. The encapsulants/lens are mainly used to prevent thermal shock and mechanical stress as well as humidity-induced corrosion. Both refractive index and good transparency of the lens are other important requirements for illumination enhancement in LEDs. Encapsulants/lens must also have high thermal conductivity, good thermal stability, superior chemical resistance, and excellent protection against moisture and degradation agents in the environment.

In addition, effective heat dissipation is important to improve the luminous output because the temperature of the device is high during operation. This high temperature of the junction is due to the presence of phosphor and also prolonged exposure to the light. To have LED lighting as a viable lighting source, many technical challenges have to be resolved. The light extraction efficiency and the light output degradation are the key issues, which are related to the packaging materials. LEDs have to operate at different temperatures and humidity environments ranging from indoor conditions to outdoor climate changes. Moisture, ionic contaminants, heat, radiation, and mechanical stresses can be highly detrimental to LEDs, and may lead to device failures. Discoloration 
and yellowing are the most common failure mechanisms. They lead to a decrease in the transparency of encapsulants and also a decrease in the LED light output. $^{9}$

Although various studies ${ }^{13-19}$ have been performed to reduce the thermal and light degradation of bisphenol-A-polycarbonate (BPA-PC), there are still many challenges to overcome, particularly when it comes to the design and production of encapsulant/lens made by BPA-PC. High heat conductivity, as well as light and heat transparency are really important for encapsulant/lens materials in the LED package.

Monolayer graphene is a one-atom-thick carbon layer which has received great attention over the past few years ${ }^{20-26}$ because of its high light transmittance, great thermal and electrical conductivities, outstanding thermal and photochemical stabilities, excellent mechanical strength, and exceptional stability against heat and light. Using a graphene coating, optical and thermal stabilities of BPA-PC can be improved. Therefore, this research aims at developing a reliable method for incorporating graphene coating(s) into encapsulant/ lens components to produce a more reliable and stable LED-based product.

\section{MATERIALS AND METHODS}

Thick BPA-PC plates with industrial purity were manufactured by injection molding. Plates of $1 \mathrm{~cm} \times 1 \mathrm{~cm}$ were then coated with a monolayer of graphene using photoresist. Three samples were coated with graphene and used in the aging tests. The structure of the remote phosphor component together with the schematics of expected functionality from the graphene coating are shown in Fig. 1. To coat the graphene on the samples, photoresist was spin-coated on $500 \mathrm{~nm} \mathrm{Cu}$ at $1600 \mathrm{rpm}$ in $30 \mathrm{~s}$. Graphene was already deposited on the $\mathrm{Cu}$ by a chemical vapor deposition (CVD) method, in which it was coated on $500 \mathrm{~nm}$ of $\mathrm{Cu}$ on $100 \mathrm{~nm}$ of $\mathrm{SiO}_{2}$ on $\mathrm{Si}(100)$ wafers as substrate. The AIXTRON BlackMagic at $900^{\circ} \mathrm{C}$ was performed using $\mathrm{CH} 4 / \mathrm{H} 2 / \mathrm{Ar}$ as feedstock with a growth time of $300 \mathrm{~s}$. A gel-pack film was applied after spin coating and then wet etching was performed by $5 \% \mathrm{FeCl} 3$ for almost $20 \mathrm{~h}$. The graphene was then stamped to the BPA-PC on a hot plate at $150^{\circ} \mathrm{C}$ for $5 \mathrm{~min}$. Subsequently, the gelpack was removed by applying heat. Finally, the photoresist was dissolved by acetone in $70^{\circ} \mathrm{C}$ for $10 \mathrm{~min}$. The process is schematically shown in Fig. 2. The transferring of the graphene and the coated graphene was performed on $\mathrm{SiO}_{2}$ using photoresist. Figure 3 illustrates the Raman spectra of the $\mathrm{Cu}$ before and after transferring the graphene on the $\mathrm{SiO}_{2}$.

Both plates with and without a graphene monolayer were aged in a furnace at $120^{\circ} \mathrm{C}$ up to $1500 \mathrm{~h}$. This process was performed to check the effects of the graphene monolayer on the chemical and optical properties of the samples, as well as the reliability and lifetime of the BPA-PC. Testing temperatures for the aging test was determined in such a way that the temperature did not exceed the glass transition temperature $(\mathrm{Tg})$ of the plastics. The glass transition temperature of $\mathrm{BPA}-\mathrm{PC}$ is $150^{\circ} \mathrm{C}$, therefore the maximum accelerated temperature was chosen below the Tg. All optical and chemical tests on the degraded specimens were performed at room temperature. Infrared spectra of the aged specimens were also recorded using a Perkin-Elmer Spectrum 100 series spectrometer in the attenuated total reflection (ATR) mode for 200 scans at a resolution of $4 \mathrm{~cm}^{-1}$. Spectral power distribution (SPD) of BPA-PC plates and the yellowing index of the thermally-aged plates were also measured by an integrated sphere. Transmission spectra of BPA-PC, in the range of 300-1200 $\mathrm{nm}$, were recoded with the Lambda 950 spectrophotometer (PerkinElmer 950).

\section{RESULTS AND DISCUSSION}

High thermal and optical transparencies are the main characterises of lens/substrates in remote phosphor plates. High transmittance of the encapsulant is one of the most important expected properties because it has a direct influence on the package efficiency and the reliability of the final product. As the graphene monolayer is very thin (about $0.34 \mathrm{~nm}$ ), and it has high light transparency, it can be used in an encapsulant/lens with hardly any adverse influence on the optical properties of the BPA-PC plate. The transparency of the BPA-PC samples with and without graphene was measured by LAMBDA spectroscopy (shown in Fig. 4). It is obvious that the effect of the graphene on the transparency of the plate is insignificant, and the BPA-PC coated with graphene has high transmittance values over 400-700 nm.

Effective heat dissipation is of crucial significance to improve the luminous output and discoloration resistance. Heat generation inside the device can cause discoloration and also a reduction in the light emission and therefore a shorter working lifetime. The monolayer of graphene does not seem to decrease the temperature on the top of the plate, either in a conductive or a convective manner. The temperature of the plates was measured by an IR camera, and thermocouple. It was found that the difference between the coated and un-coated samples was insignificant. In an attempt to enhance the thermal conductivity of the coating, a multilayer coating of graphene was applied to the plates. This did not really work since the multilayer of graphene is black and it dramatically decreases the light transmission.

Figure 5 illustrates the FTIR-ATR spectra of a sample aged at $120^{\circ} \mathrm{C}$ for $1500 \mathrm{~h}$ in both the coated and non-coated conditions. In this figure, the appearance of the peak at $1840 \mathrm{~cm}^{-1}$ is an indication of thermal oxidation. It has already been 
(a)

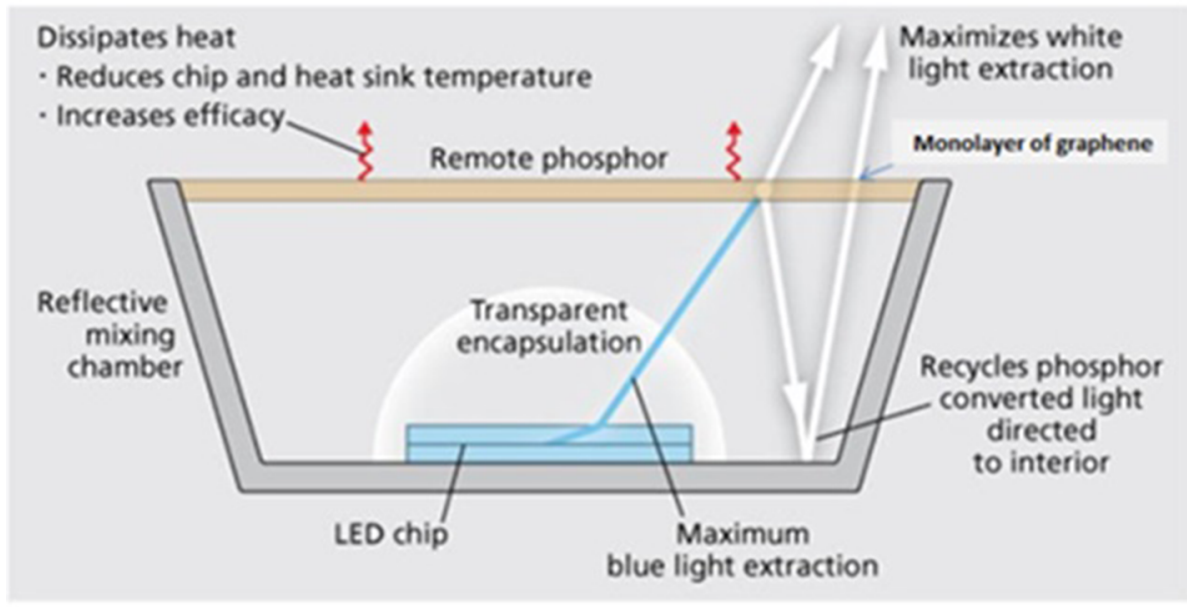

(b)

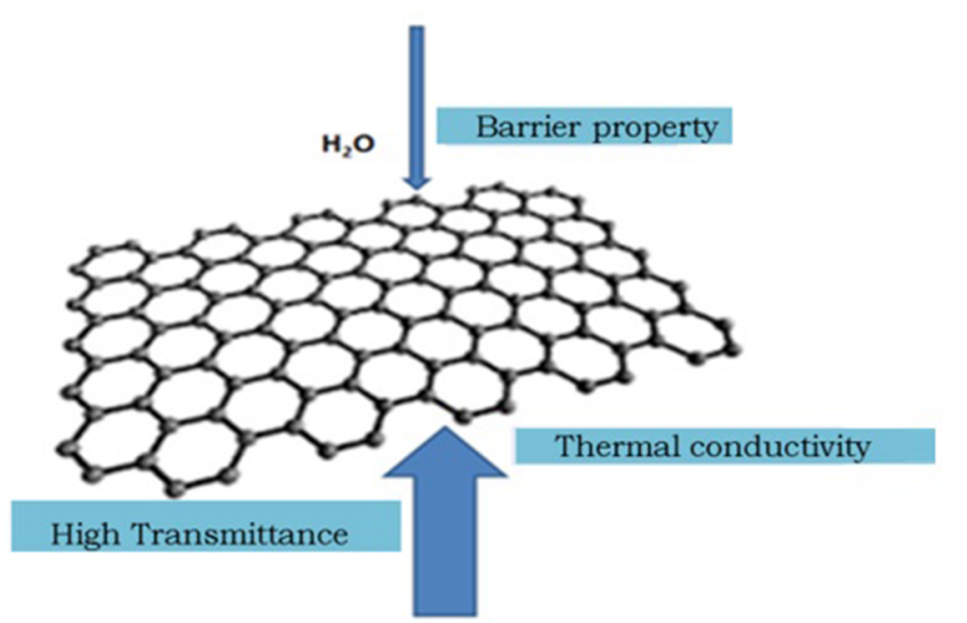

Fig. 1. (a) Schematic illustrating the remote phosphor white LED device structure. The remote phosphor is a protective BPA-PC coated by YAG:Ce layer designed to convert blue light to yellow light. (b) Schematic summary of the function of graphene monolayer in the remote phosphor.

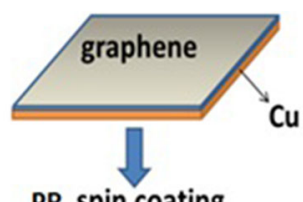

PR spin coating

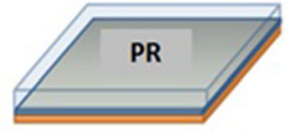

Cu etching

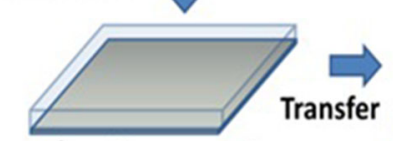

PR /graphene membrane

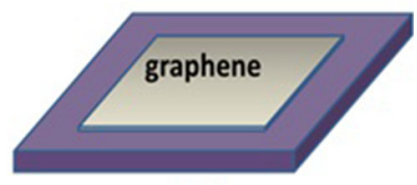

Dissolving PR

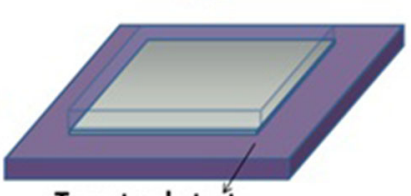

Target substrate

Fig. 2. Schematic of transferring graphene to the BPA-PC plates.

reported that $1840 \mathrm{~cm}^{-1}$ (cyclic anhydrides) ${ }^{14,16}$ in the carbonyl region would appear in all temperatures as a result of thermal oxidation. These

oxidation products could significantly contribute to the discoloration of thermally-aged specimens. Since samples are commercial ones and have different additives and stabilizers, and the increase in the peak intensity is not large compared to pure samples. ${ }^{16}$ However, it is obvious that the rate of oxidation in samples coated with graphene is comparatively smaller than that of the samples without the coating. One can therefore conclude that the samples with the graphene coating are comparatively less oxidized.

The ability to protect a device from the external environment is essential for long-term operation and high luminous efficiency. Encapsulants/lens having poor protective properties are prone to early oxidation. The power conversion efficiency of a white LED (including the encapsulant) as a function of the graphene layer was studied using moisture tests. The moisture barrier behavior was determined by measuring the weight increase of a 2-mmthick specimen after being saturated in water at $45^{\circ} \mathrm{C}$ for $100 \mathrm{~h}(100 \% \mathrm{RH})$. It has previously been reported that, by increasing the exposure time in 

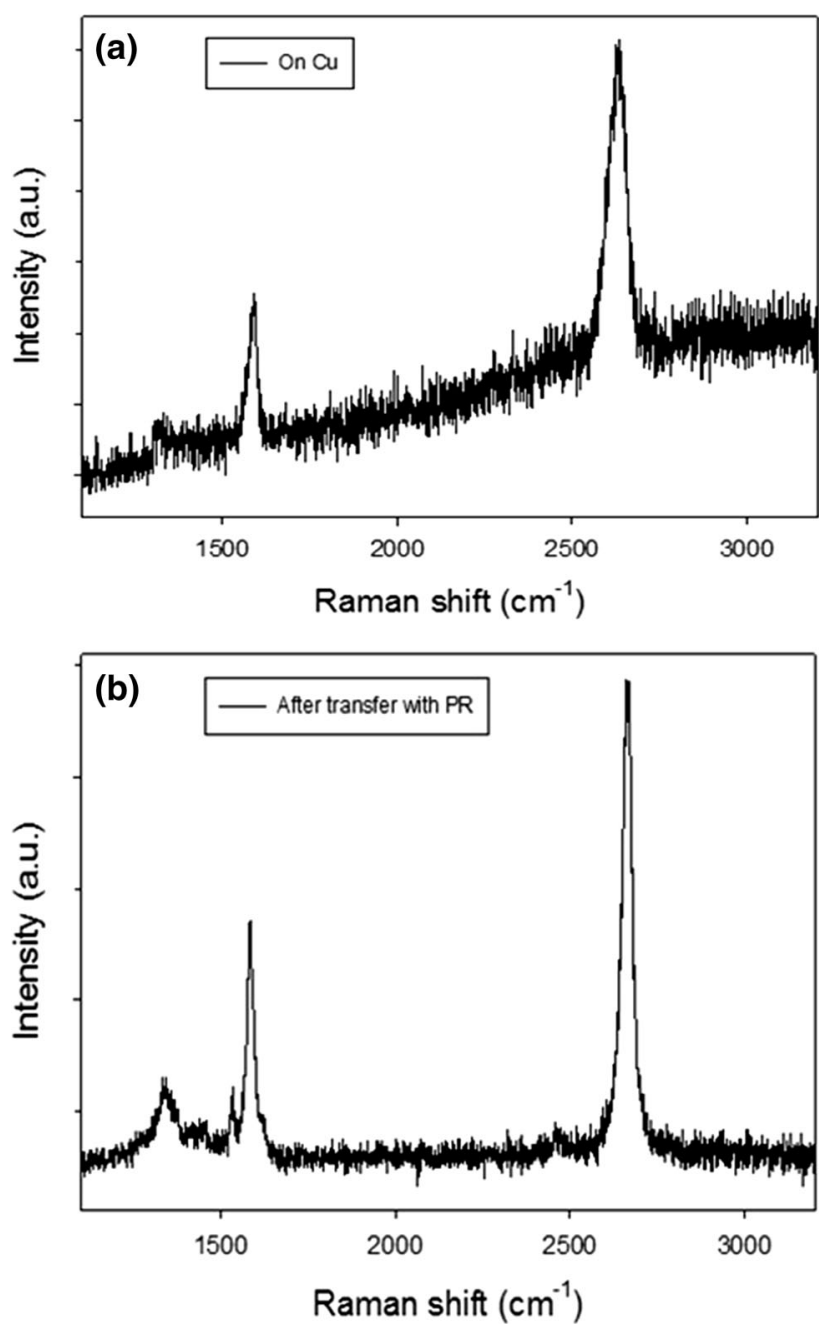

Fig. 3. Spectra of transferring graphene to the $\mathrm{SiO}_{2}$ plates (a) Before transferring, (b) After transferring by photoresist.

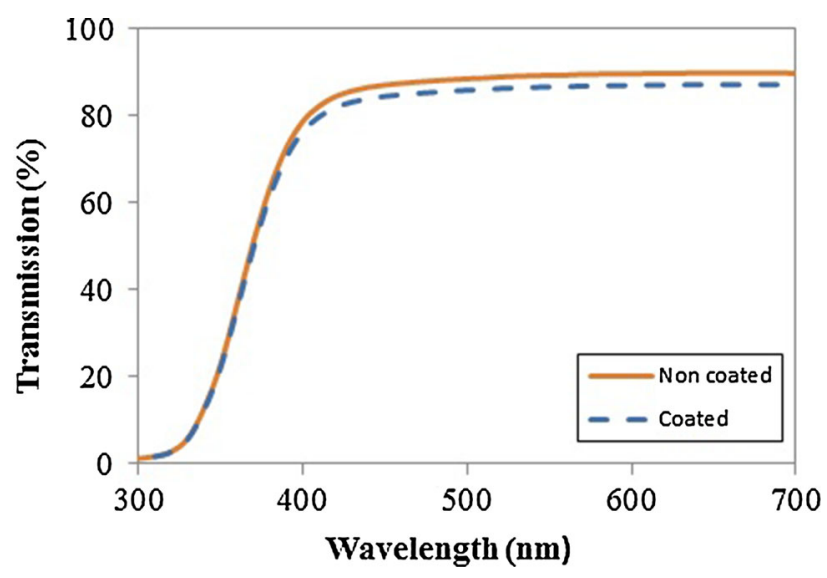

Fig. 4. Effect of graphene on transparency of BPA-PC.

$100 \%$ humidity condition, the weight of the samples increases due to water absorption. ${ }^{24}$ The amount of absorbed water in the polymer is measured by the following equation:
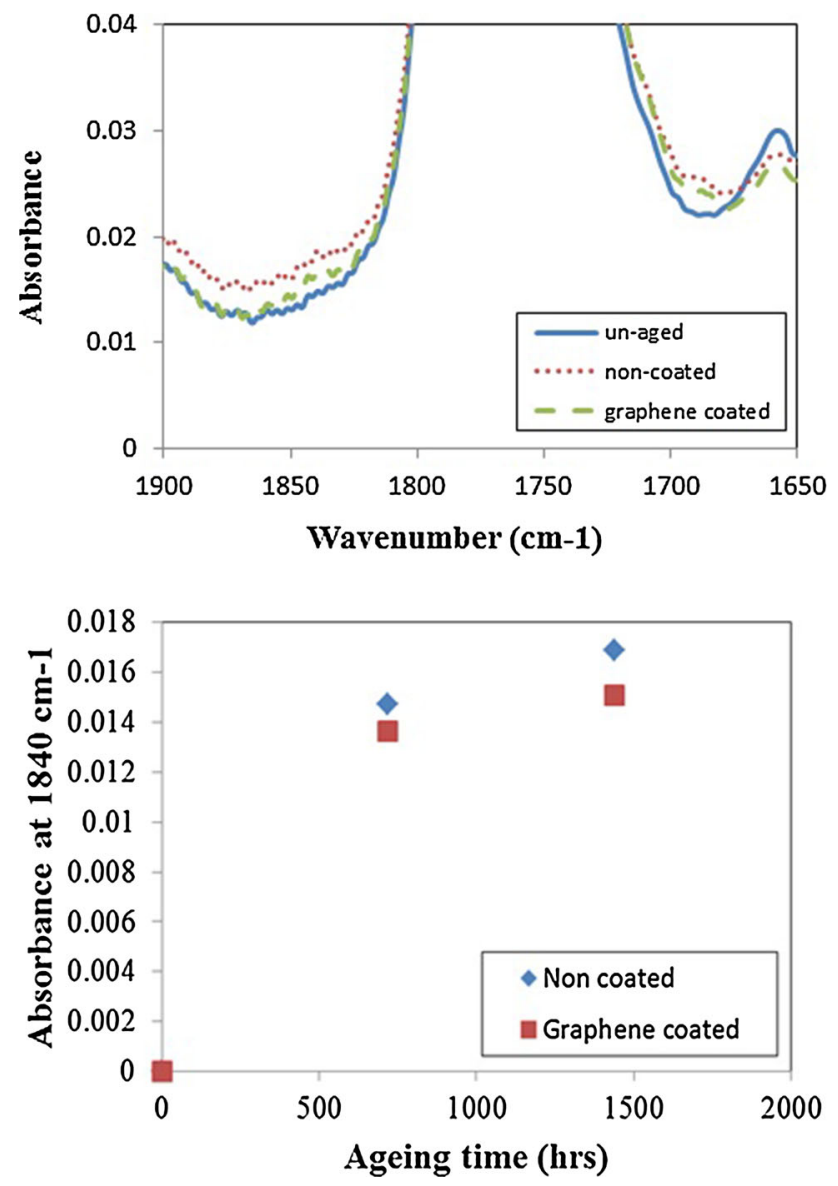

Fig. 5. Oxidation of PC plates with and without graphene.

$$
\text { Water Content }=\frac{\left(M_{\mathrm{t}}-M_{0}\right)}{M_{0}}
$$

where $M_{\mathrm{t}}$ is the weight of the sample saturated in water at time $t$, and $M_{0}$ is the initial weight of the sample. With increasing the time, the weight of water absorption increases in both samples. However, the graphene coating reduces the weight gain compared to the un-coated samples, as shown Fig. 6. A clear difference between the kinetics of water uptake in the un-coated and graphene-coated specimens is observed, with the latter showing a remarkably slower kinetics. It has been reported that graphene is a good barrier against water and gas. $^{26,27}$ Water molecules cannot easily enter through the graphene. As a result, graphene can act as an obstacle against moisture penetration.

Moreover, the optical properties of thermallyaged plates, i.e. luminous flux depreciation, were studied at room temperature using an integrated sphere. The Commission International de l'Eclairage (CIE) system is the common method to characterize the composition of any color in terms of three primaries. ${ }^{12}(x, y)$ is usually used to represent the color. To obtain the reasonably equidistant chromaticity scales, which are better than the CIE 
1931 diagram, the CIE 1976 uniform chromaticity scale (UCS) diagram was used. This diagram is called $\left(u^{\prime}, v^{\prime}\right)$. The $\left(u^{\prime}, v^{\prime}\right)$ coordinates are related to the $(x, y)$ coordinates by the following equations:

$$
\begin{aligned}
U^{\prime} & =\frac{4 x}{-2 x \times 12 y \times 3} \\
V^{\prime} & =\frac{9 y}{-2 x \times 12 y \times 3}
\end{aligned}
$$

$\Delta u^{\prime} v^{\prime}$, which defines the color shifting at any two positions ( 0 and 1$)$, can be calculated using the following formula,

$$
\Delta u^{\prime} v^{\prime}=\sqrt{\left(u_{1}^{\prime}-u_{0}^{\prime}\right)+\left(v_{1}^{\prime}-v_{0}^{\prime}\right)}
$$

Energy Star specifies that color maintenance must not exceed $\Delta u^{\prime} v^{\prime}=0.007$ on the CIE $u^{\prime} v^{\prime}$

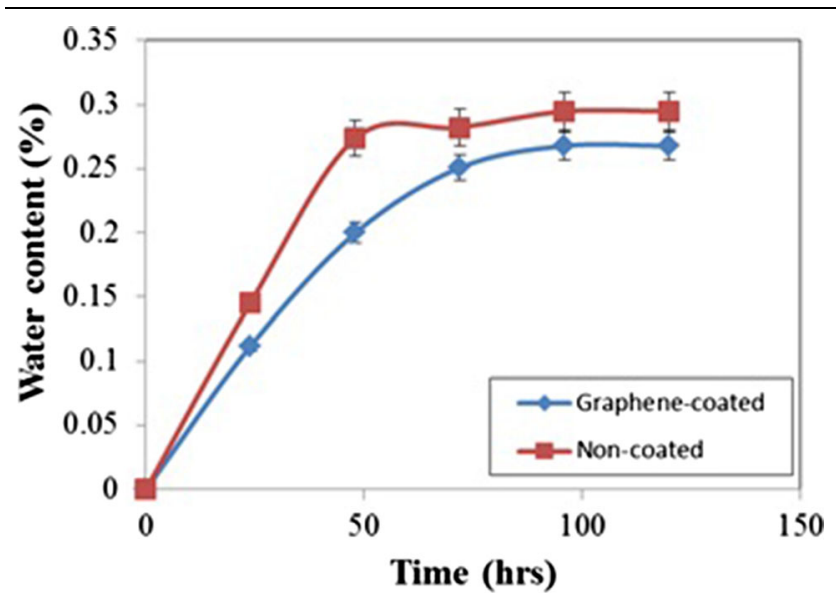

Fig. 6. Water content of PC plates with and without graphene. diagram, after $6000 \mathrm{~h}$ of operation. Color shifting in thermally-aged specimens, calculated by Eq. 3, is shown in Fig. 7. As can be seen in this figure, the color shifting of un-coated and graphene-coated BPA-PC plates is less than the criteria of color shifting in white light. However, yellowing and discoloration of samples coated with graphene are comparatively lower than for the un-coated samples.

The effect of graphene on the thermal aging of BPA-PC is shown in Fig. 8. Stress at a high temperature level can cause thermal aging and consequently depreciation of light output. This is shown in Fig. 8 for the case of thermal aging for a non-coated sample and a coated one. One can confer from this figure that the reduction of radiant power in the coated sample is less than that in the noncoated one.

Luminous flux reduction in both samples is shown in Fig. 9. It can be seen in this figure that graphene considerably improves the optical output of BPAPC. As explained before, the lifetime of LEDs is defined as the time to reach $70 \%$ of initial lumen output based on the ASSIST standard. ${ }^{15}$ Therefore, the extrapolation of experimental data is needed. Given that the reaction rate is assumed to be constant at each temperature, $a$ at temperature $T$ is calculated as follows:

$$
a(T)=\frac{-\ln [\phi(t)]}{t}
$$

To calculate $a$ at each temperature, $t$ is taken equal to the time when lumen decays to 0.9 . This $t$ is obtained experimentally. Having the reaction rate at each temperature, the time for $70 \%$ lumen decay

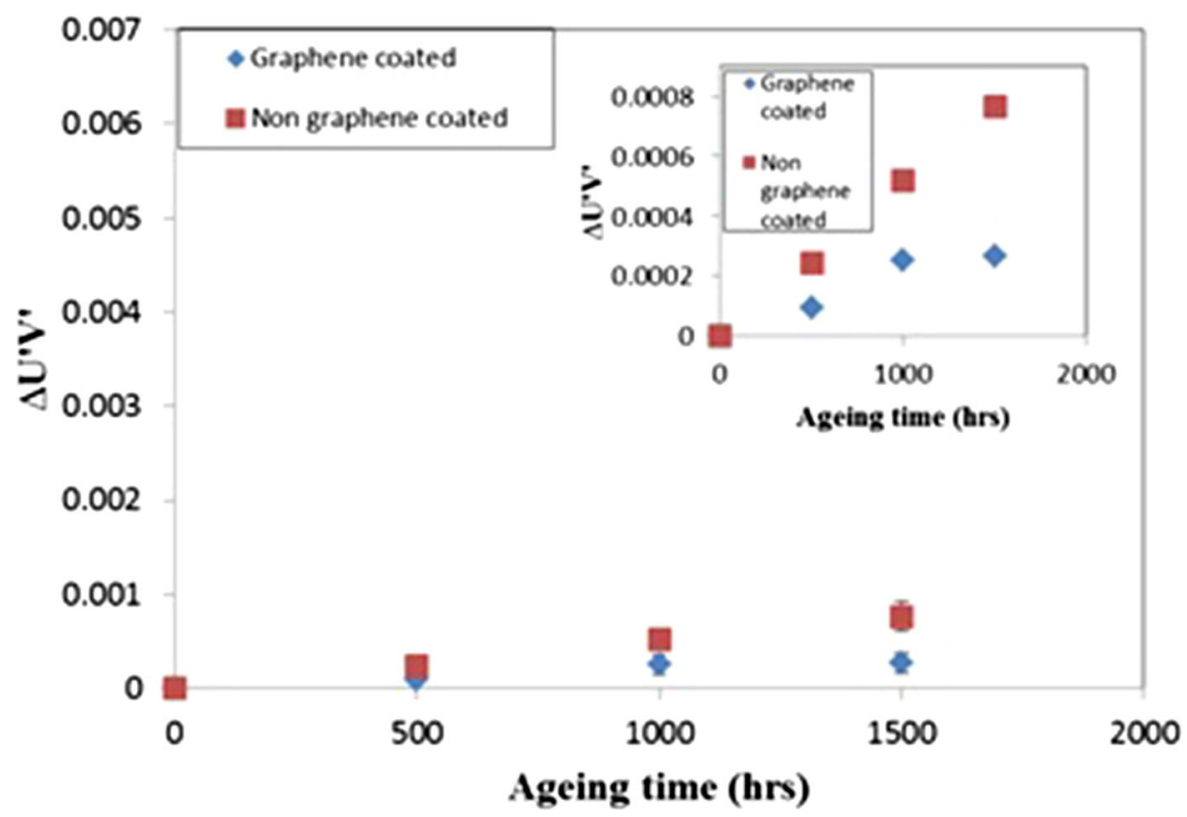

Fig. 7. Variation in discoloration of BPA-PC plates with and without graphene. 


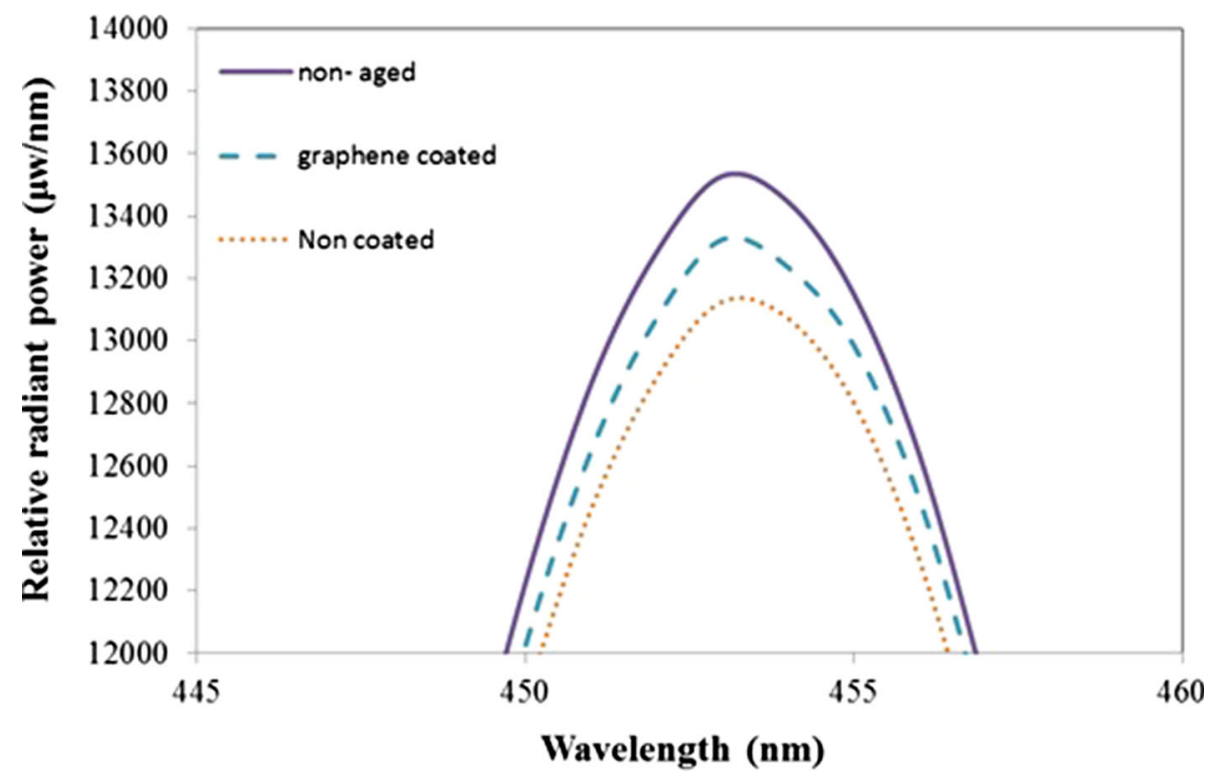

Fig. 8. Relative radiant power of remote phosphor plates at $120^{\circ} \mathrm{C}$.

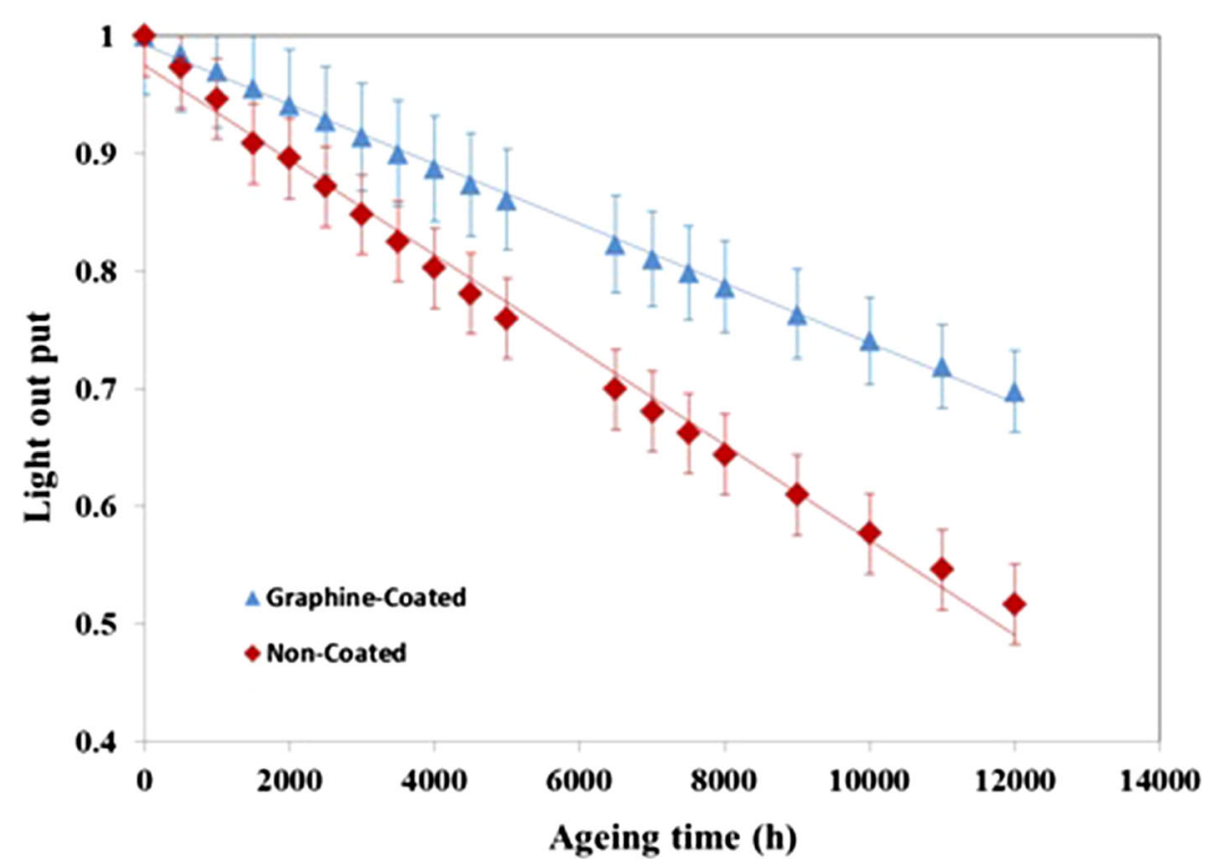

Fig. 9. Normalized flux of light as a function of aging hours for un-coated and coated samples.

can then be easily calculated. Consequently, the calculated $a$ can be used to extrapolate the lumen decay until $70 \%$ at each temperature (see dashed lines in Fig. 9). Based on the experimental results and the extrapolation procedure explained above, it is shown that the time needed to achieve $70 \%$ of lumen output is $6500 \mathrm{~h}$ for un-coated BPA-PC. This time is around $12,000 \mathrm{~h}$ for graphene-coated BPA-
PC plates, which would imply that the monolayer of graphene can improve the lifetime of the BPA-PC by a factor of 2 .

\section{CONCLUSIONS}

Significant improvements in optical properties as well as the reliability and lifetime of BPA-PC plates 
are observed by applying a graphene layer on the BPA-PC. A graphene monolayer acts as a barrier against oxygen and moisture diffusion. The graphene-coated PC was then used as lens/substrate in remote phosphor in the LED-based products. This resulted in a slower kinetics of oxidation and discoloration. The addition of relatively small amount of graphene can improve lthe ong-term stability and reliability of LEDs.

\section{ACKNOWLEDGEMENTS}

The authors would like to acknowledge the "TNO innovation for life" company for SPD measurements. They would also like to thank Prof. Picken for his useful suggestions and discussions. They gratefully acknowledge Isfahan University of Technology (IUT) and Nokhbegan foundation for their support.

\section{OPEN ACCESS}

This article is distributed under the terms of the Creative Commons Attribution 4.0 International License (http://creativecommons.org/licenses/by/4.0/), which permits unrestricted use, distribution, and reproduction in any medium, provided you give appropriate credit to the original author(s) and the source, provide a link to the Creative Commons license, and indicate if changes were made.

\section{REFERENCES}

1. S. Nakamura and G. Fasol, (Springer, Berlin, 1997), p. 216.

2. E.F. Schubert, Light-Emitting Diodes (Cambridge: Cambridge University Press, 2003), p. 245.

3. P. Mottier, LEDs for Lighting Applications (Hoboken: Wiley, 2009), pp. 2-26.

4. R. Mueller-Mach and G.O. Mueller, Proc. SPIE 3938, 30-41 (2000).

5. M.H. Chang, D. Das, P.V. Varde, and M. Pecht, Microelectron. Reliab. 52, 762 (2012).
6. R. Mueller-Mach, IEEE J. Sel.Top. Quantum Electron. 82, 339 (2002).

7. M. Yamada, Jpn. J. Appl. Phys. 42, L20 (2003).

8. U.S. Department of Energy, Solid-State Lighting Research and Development: Multi-Year Program Plan (Washington: U.S. Department of Energy Report, 2013).

9. Illuminating Engineering Society of North America, Projecting Long Term Lumen Maintenance of LED Light Sources. IES Report TM-21 11 (New York, 2011).

10. M. Meneghini, L. Trevisanello, S. Podda, S. Buso, G. Spiazzi, G. Meneghesso, and E. Zanoni, Proc. SPIE 633, 14 (2006).

11. M. Meneghini, L. Trevisanello, C. Sanna, G. Mura, M. Vanzi, G. Meneghesso, and E. Zanoni, Microelectron. Reliab. 47, 1625 (2007).

12. N. Narendran, Y. Gu, J.P. Freyssinier, H. Yu, and L. Deng, J. Cryst. Growth 268, 449 (2004).

13. N. Narendran, Y. Gu, J.P. Freyssinier, and H. Yu, Phys. Status Solidi(A) Appl. Res. 202, R60 (2005).

14. M. Yazdan Mehr, W.D. van Driel, K.M.B. Jansen, P. Deeben, and G.Q. Zhang, Microelectron. Reliab. 54, 138 (2014)

15. M. Yazdan Mehr, W.D. van Driel, and G.Q. Zhang, Microelectron. Reliab. 54, 1544 (2014).

16. M. Yazdan Mehr, W.D. van Driel, S. Koh, and G.Q. Zhang, Microelectron. Reliab. 54, 2440 (2014).

17. M. Yazdan Mehr, W.D. van Driel, H. Udono, and G.Q. Zhang, Opt. Mater. 37, 155 (2014).

18. B.F. Fan, H. Wu, Y. Zhao, Y.L. Xian, and G. Wang, IEEE Photon. Technol. Lett. 19, 1121 (2007).

19. M.D. Lago, M. Meneghini, N. Trivellin, G. Mura, M. Vanzi, G. Meneghesso, and E. Zanoni, Microelectron. Reliab. 52, 2164 (2012).

20. Z. Liu, J. Li, Z.-H. Sun, G. Tai, S.P. Lau, and F. Yan, ACS Nano 6, 810 (2012).

21. Z.-S. Wu, W. Ren, L. Wen, L. Gao, J. Zhao, Z. Chen, G. Zhou, F. Li, and H.M. Cheng, ACS Nano 4, 3187 (2010).

22. D. Wang, R. Kou, D. Choi, Z. Yang, Z. Nie, J. Li, L.V. Saraf, D. Hu, J. Zhang, and G.L. Graff, ACS Nano 4, 1587 (2010).

23. H. Kim, Y. Miura, and C.W. Macosko, Chem. Mater. 22, 3441 (2010).

24. I.-H. Tseng, Y.-F. Liao, J.-C. Chiang, and M.-H. Tsai, Mater. Chem. Phys. 136, 247 (2012).

25. T.-H. Han, Y. Lee, M.-R. Choi, S.-H. Woo, S.-H. Bae, B.H. Hong, J.-H. Ahn, and T.-W. Lee, Nat. Photon. 6, 105 (2012).

26. K. Hyunwoo, Y. Miura, and C.W. Macosko, Chem. Mater. 22, 3441 (2010).

27. S. Lee, J.-Y. Jang, and J. Hong, ACS Nano 7, 5784 (2013). 